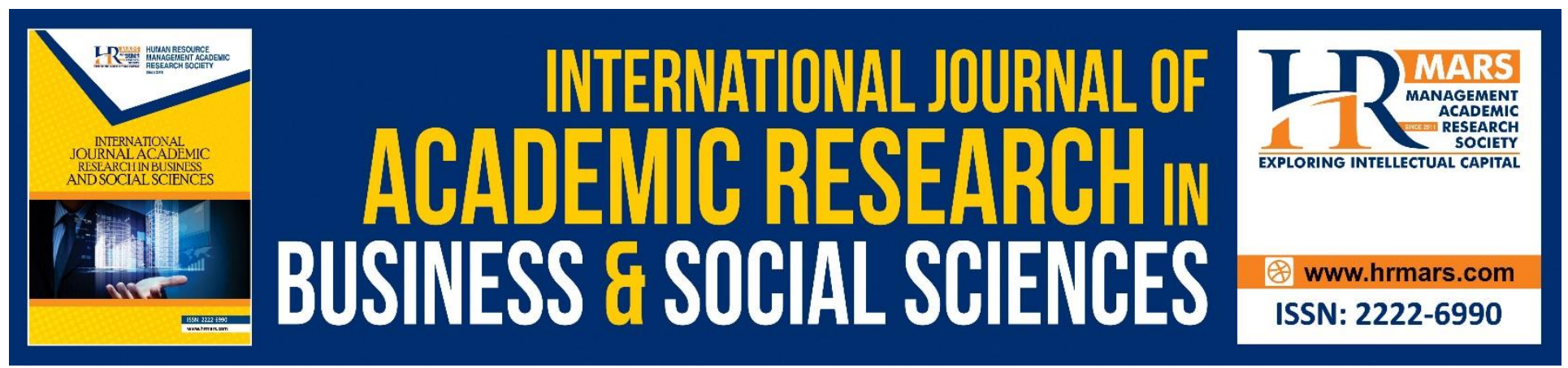

\title{
Factors Influencing Behavioral Intention in Online Health Information Seeking among Public University Students
}

Nor Intan Shamimi A.A., Nurul' Aini M.Z.

To Link this Article: http://dx.doi.org/10.6007/IJARBSS/v8-i7/4390

DOI: $\quad 10.6007 /$ IJARBSS/v8-i7/4390

Received: 24 May 2018, Revised: 19 June 2018, Accepted: 29 June 2018

Published Online: 28 July 2018

In-Text Citation: (Nor Intan Shamimi \& Nurul' Aini, 2018)

To Cite this Article: Nor Intan Shamimi, A. ., \& Nurul' Aini, M. Z. (2018). Factors Influencing Behavioral Intention in Online Health Information Seeking among Public University Students. International Journal of Academic Research in Business and Social Sciences, 8(7), 490-499.

\section{Copyright: (C) 2018 The Author(s)}

Published by Human Resource Management Academic Research Society (www.hrmars.com)

This article is published under the Creative Commons Attribution (CC BY 4.0) license. Anyone may reproduce, distribute, translate and create derivative works of this article (for both commercial and non-commercial purposes), subject to full attribution to the original publication and authors. The full terms of this license may be seen

at: http://creativecommons.org/licences/by/4.0/legalcode

Vol. 8, No. 7, July 2018, Pg. 490 - 499

http://hrmars.com/index.php/pages/detail/IJARBSS

JOURNAL HOMEPAGE

Full Terms \& Conditions of access and use can be found at http://hrmars.com/index.php/pages/detail/publication-ethics 


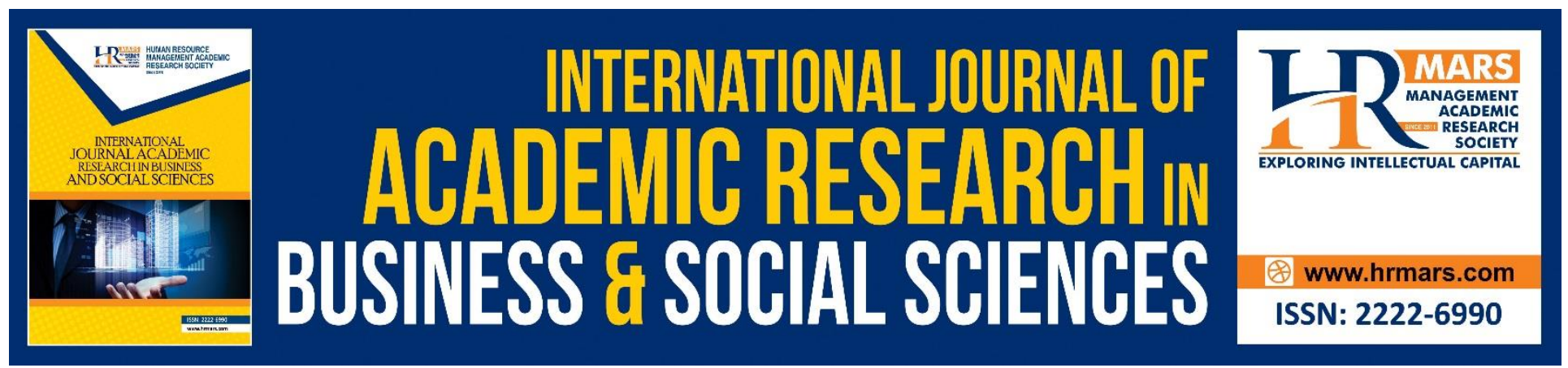

\title{
Factors Influencing Behavioral Intention in Online Health Information Seeking among Public University Students
}

\author{
Nor Intan Shamimi A.A., Nurul' Aini M.Z. \\ Universiti Teknologi MARA, Malaysia
}

\begin{abstract}
Medical issues or any health-related matters can be derived not only from professionals as the main source in secure the information, but technological advancement system makes people turned to the Internet as the platform to seek for a diverse range of health-related information (HRI). The number of educated society has continued to grow tremendously for them to explore thousands of health websites which they can refer to related diseases. However, HRI is not given focus for its importance compared with other online activities. Lacking in health literacy also contributes to the society weakness in understanding the health articles posted over the Internet. Therefore, this crosssectional study aims to assess demographic profile as the factors influencing behavioral intention in online health information seeking among undergraduate students. A self-administered questionnaire was used to collect data from 150 students. This study has found two significant factors that influenced the behavioral intention in seeking HRI. The findings therefore will highlight certain issues on the importance of expanding knowledge such as health and information literacy and to promote self-care management among the students.
\end{abstract}

Keywords: Health-related information · Online health information seeking ·Behavioral intention

\section{Introduction}

Internet is an effective medium of communication that helps to reduce complex information needs by healthcare professional and medical education (Jadoon et al., 2011). Development and evolution of Internet for health-related purposes has been growing rapidly and has bought huge changes in the healthcare delivery systems across the globe from educations and training until to diagnosis and patient management (Lee, Hoti, Hughes and Emmerton, 2014). An increasing number of general population use it to search for all kinds of information including health-related information such as educational material, access to online databases, exploring the application of theoretical ideas and use of various interactive tools to enhance understanding of complex ideas (Jadoon et al., 2011).

eHealth, a well-known term for electronic health information emcompasses the use of information and communication technologies (ICTS) in the support of halth and health-related activities. The potential to provide innovative solutions to health problems is enourmous. Many see 
INTERNATIONAL JOURNAL OF ACADEMIC RESEARCH IN BUSINESS AND SOCIAL SCIENCES Vol. 8, No. 7, July 2018, E-ISSN: 2222-6990 @ 2018 HRMARS

eHealth solutions as the 'magic bullet' to solve numerous unsolved problems related to healthcare. Information and communication technology are expected to reuce the burden of disease, to improve healthcare delivery and the experience of care for those living with chronic diseases. The evolution of eHealth created another subset which is mHealth which delivers the same function as eHealth. The only difference between these two technologies is mHealth use mobile communication devices for health services and information (Saner, 2016; Klonoff, 2013). Thus, the adoption of online health information services should be easy to understand and use to close the information gap resulting from scarcity of resources (Cline and Haynes, 2001).

Apart from all the advantages from the implementation of ICTs in healthcare industry, there are several concerns need to be addressed to improve the effectiveness of Health-related information (HRI) among the society. Some previous studies have found that empowering citizens in relation to health information searching online is not been concerned in Malaysia. Perhaps it is due to overworked of medical professionals. Generally, Malaysia had 17.7 million Internet users nationwide and they spend almost 20 hours per week online. Three main activities related to the user preferances are downloading or streaming videos, spending time on social networking sites and entertainment. (Norfadzila, Balakrishnan and Abrizah, 2012). Moreover, online health information deserves attention because studies on the content of HRI websites highlighted inaccuracies that raise concern about the quality of information encountered by consumers (Diviani, Putte, Giani, and Weert, 2015). Consumers can access online health information directly from credible scientific and instituitional sources such as Medline or Healthfinder. They may also can access to unreviewed sources of unknown credibility (Cline and Haynes, 2001). Health information can be inaccurate and confusing to the consumer without proper guidelines.

The present study assesses demographic profile as the factors influencing behavioral intention in online health information seeking among undergraduate students. The objectives of the study is to compare the factors influencing online health information seeking among students.

In addition, this study also provides research hypotheses to predict the assumptions in comparing the following mean variables; gender, marital status, course programs, frequencies in seeking information and health status.

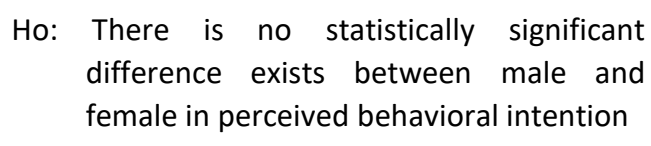

Ho: There is no statistically significant difference exists between single and married status in perceived behavioral intention

Ho: There is no statistically significant difference exists between course programs in perceived behavioral intention

Ho: There is no statistically significant difference exists between the frequencies in nerceived hehavioral intention 
Ho: There is no statistically significant difference exists between respondents' health status in perceived behavioral intention

\section{Methodology}

Research Design: This study applied cross-sectional descriptive design.

Settings and Sample: The study was conducted in one public university in the area of Bandar Puncak Alam, Selangor by using convenience sampling method used at Faculty of Business Management in two centres; Center for Management and Administrative Studies (Bachelor's Degree in Health Administration, Event Management, Human Resource and International Business) and Center for Economics and Finance Studies (Bachelor's Degree in Insurane, Finance, Islamic Banking and Business Economics). All the undergraduate students must be enrolled in any of the programs listed in these centres and agree to particate in this survey. In total, the number of registered students were 2,500 for session of March-July 2017 intake. Based from Salkind (2009), the appropriate sample size should be more than 30 or less than 500 . Thus, this study proposed to select 150 students as respondents.

Instrument: A self-administered multi-lingual (English and Malay Language) questionnaire was used in conducting this survey based on a five-likert scale ranging from strongly agree (1) to strongly disagree (5). A likert item is simply a statement which the respondent is asked to evaluate according to any kind of subjective or objective criteria, generally the level of agreement or disagreement is measured (Norfadzila, Balakrishnan and Abrizah, 2012). Precisely, it has two categories: category A includes demographic background such as age, gender, marital status, registered program and health status while in category B includes behavioral intention towards HRI. Approximately 5-10 minutes were spent for this survey.

Procedures: To start with data collection, students were approached by the end of their lectures and briefly explained on this study and how to answer the questionnaire. To ensure the smoothness of answering the survey, volunteer students answered the questionnaire less than 5 minutes before they leave the classes. In order to avoid redundancy in answering the survey, they have been asked not to participate in their next classes.

\section{Results}

\section{Demographic Profiles}

In the previous chapter, this study has identified several characteristics as the independent variables. In order to test the hypotheses, an independent t-test was performed. A Table 1 has presented a summary of t-test result below. The number of female respondents $(n=91)$ are greater $(m=3.40$, $\mathrm{SD}=.451)$ compared to male $(n=59)$ in terms of gender $(m=3.25, S D=.541)$. The assumptioms of homogeneity of variances was tested through Levene's Test for Equality of Variances $(F=.055, p=$ .815). The t-test then, showed a slightly not significant result by having $p=.079$. Thus, the first hypothesis is not rejected as there is no statistically different exists between male and female in perceived behavioral intention of online health information seeking. 
INTERNATIONAL JOURNAL OF ACADEMIC RESEARCH IN BUSINESS AND SOCIAL SCIENCES Vol. 8, No. 7, July 2018, E-ISSN: 2222-6990 @ 2018 HRMARS

Most of this university students are single $(n=139, m=3.35, S D=.455)$ compared to those who are married $(n=11, m=3.26, S D=.862)$. The result from Levene's Test also was done with $F=$ 7.27 and $p=.008$. For $t$-test result, however, it is showed a not statistically significant effect with $p=$ .741. Due to that, null hypothesis is not rejected where there is no difference on the influence of behavioral intention between single and married person towards online health information seeking.

This study also divides the students according to centers or department in the faculty. The students enrolled in Center for Economics and Finance Studies (CfEFS) contributes more in this survey ( $\mathrm{n}=54, \mathrm{~m}=3.43, \mathrm{SD}=.556$ ) compared to the students joined Center for Management and Administrative Studies (CfMAS) $(n=52, m=3.16, S D=.419)$. In Levene's Test score $(F=1.62)$, a statistically not significant result is showed $(p=.206)$. Nevertheless, t-test result had brought up a significant result by having $p=.005$. Because of that, null hypothesis is rejected. It is to explain that different course programs are actually influenced students' behavioral intention in seeking online health information.

When the students have been asked how frequent do they search for online health information, the result showed that most of them are still not aware of having ehealth literacy $(\mathrm{n}=$ $89, \mathrm{~m}=3.28, \mathrm{SD}=.503$ ) compared to those who already familiar to look for health information online ( $n=61, m=3.43, S D=.466)$. For assumptioms of homogeneity of variances in Levene's Test, the score is $F=.001$ and $p=.970$, bringing the t-test score with a not significant effct of $p=.067$. Thus, hypothesis is not rejected, and it means that, the importance of health information and quality of life is not a serious issue for these young adult. It is explained that it does not affect their intention to seek for online health information.

The health of respondents has been divided into two; good and poor. Most of them are in a good health condition $(n=108, m=3.41, S D=.419)$ compared to those who were sick $(n=42, m=$ $3.15, \mathrm{SD}=.607$ ) during participate in this survey. The Levene's Test homogeneity of variances reported a score of not significant effect, $F=1.83, p=.179$. For $t$-test result, it is showed a statistically significant by having $p=.002$. Null hypothesis is rejected and the reason behind it is because, health status affects their intention to seek online health information. Usually, the person with a health problem keen to explore the useful information over the Internet. 
INTERNATIONAL JOURNAL OF ACADEMIC RESEARCH IN BUSINESS AND SOCIAL SCIENCES Vol. 8, No. 7, July 2018, E-ISSN: 2222-6990 @ 2018 HRMARS

Table 1: t-test Results Comparing Demographic Profiles Behavioral Intention of Online Health Information Seeking.

\begin{tabular}{|c|c|c|c|c|c|c|c|}
\hline Grade Level & $n$ & Mean & SD & $\mathrm{t}$ & df & $p$ & Decision \\
\hline \multicolumn{8}{|l|}{ Gender } \\
\hline Male & 59 & 3.25 & 0.541 & -1.77 & 148 & 0.079 & Do Not Reject \\
\hline Female & 91 & 3.40 & 0.451 & & & & \\
\hline \multicolumn{8}{|l|}{ Marital Status } \\
\hline Single & 139 & 3.35 & 0.455 & 0.339 & 10.445 & 0.741 & Do Not Reject \\
\hline Married & 11 & 3.26 & 0.862 & & & & \\
\hline \multicolumn{8}{|l|}{ Programs } \\
\hline CFMAS & 52 & 3.16 & 0.419 & -2.855 & 104 & 0.005 & Reject \\
\hline CFEFS & 54 & 3.43 & 0.556 & & & & \\
\hline \multicolumn{8}{|l|}{ Frequencies } \\
\hline Often & 61 & 3.43 & 0.466 & 1.848 & 148 & 0.067 & Do Not Reject \\
\hline Less Often & 89 & 3.28 & 0.503 & & & & \\
\hline \multicolumn{8}{|l|}{ Health Condition } \\
\hline Good & 108 & 3.41 & 0.419 & 3.094 & 148 & 0.002 & Reject \\
\hline Poor & 42 & 3.15 & 0.607 & & & & \\
\hline
\end{tabular}

\section{Behavioral Intention}

Table 2: Mean and Standard Deviation of Behavioral Intention

\begin{tabular}{|c|c|c|}
\hline $\mathbf{N}$ & Mean & SD \\
\hline $\mathbf{1 5 0}$ & 3.3388 & .49187 \\
\hline
\end{tabular}

Table 2 provides the mean and standard deviation of behavioral intention for the total students involved in this survey. The mean scores report is 3.3388 while the standard deviation is reported .49187.

\section{Discussion}

The present study addressed associated factors which influenced the behavioral intention in online health information seeking among these undergraduate students. The first finding of this study is there are no difference in gender in online health information seeking. It can be clarified that even though $p \leq 0.05$ ( $p=0.079)$ is slightly higher, behavioral intention does not affect both gender in seeking HRI among these undergraduate students. Either male or female, they can have the intention of seeking $\mathrm{HRI}$ and seems to have an equal understanding on health topics. However, this result is contradicting with other previous studies that with regard to gender specific, it shows that women are more engaged in health information seeking in general as well as on the Internet, specifically. Women report to be more interested in health information and show more active search activities whereas men are less likely to read health information (Baumann, Czerwinski and Reifegerste, 2017). Indeed, being female, younger and having a higher level of educational attainment are all associated with more frequent health-related use of the Internet (Rowley, Johnson and Sbaffi, 2017). Thus, intention to seek HRI is depending on the individual itself to look further on the matter and how important is the information towards them. 
INTERNATIONAL JOURNAL OF ACADEMIC RESEARCH IN BUSINESS AND SOCIAL SCIENCES Vol. 8, No. 7, July 2018, E-ISSN: 2222-6990 @ 2018 HRMARS

The present study also revealed that marital status represents the same result where there is no difference between single and married person in perceived behavioral intention towards online health information seeking. It means that, relationship status has no effect on individual's intention to seek for online health information. This marital status has an inconsistent or different view regarding the intention to seek HRI. One supporting study by Siliquini et al. (2011), claimed that a higher probability of health information seeking on the Internet for people living alone compared to people in a steady relationship or married people. Nevertheless, another previous finding has found different views which is married couples or people in a stable relationship (81.7) are more likely to conduct online health searches than singles (18.3). It is probably due to stronger social ties in relationships as people in a relationship seek health information on the Internet not only for themselves, but also for their spouses or partners (Nolke, Mensing, Kramer and Hornberg, 2015). Thus, the awareness and importance of health literacy is depending on the intention of people to act fast in solving health problems regardless of their marital status.

This study also conducted the survey among students who enrolled in different course background. The results showed a significant effect with $p$ value is less than $0.05(p=0.005)$. The result indicates the relation between educated people and their behavioral intention to seek for HRI. It is supported by some of the previous finding saying that participants with more education were more likely to use the Internet as a source of health information. Another study also found on the effectiveness of having high education mentioned that female, higher education and age would contribute in having intention in online health information seeking (Jacobs, Amuta and Jeon, 2017). Another previous study also had a positive outcome regarding the online health information seeking relating those who are educated, earn more and have a high-speed Internet across at home and at work (Higgins, Sixsmith, Barry and Domegan, 2011). In other words, education plays a vital role in influencing students to perceive in behavioral intention on online health information seeking.

Furthermore, the frequency of how often they seek for online health information were also discovered in the survey. The result showed a slightly not significant of the $p$ value indicating that the frequency in searching for HRI does not associate in perceiving their behavioral intention. This is also reflected in their survey where students with less searching for HRI is counted as higher compared to those with more often searching for the information. In contrary, a previous study on the awareness of HRI has been done among Ghanaian university students. It has a good result with majority of the student use internet for health purpose with 440 over 205 participants. It showed the level of awareness on health is high among those students in that university (Asibey, Agyemang and Dankwah, 2017). The most obvious finding to emerge from this study is the importance of health awareness among university students in Malaysia. Increasing towards health awareness needs attention to improve quality of life. Several previous studies have found an increasing use of the Internet for health purpose among students. Escoffery et al. (2005) in the study among college students in the US showed that the use of Internet is rising. Specifically, the study showed that more than $70 \%$ of the respondents had used online health information and more than $40 \%$ reported using it frequently (Obasola and Agunbiade, 2016). 
INTERNATIONAL JOURNAL OF ACADEMIC RESEARCH IN BUSINESS AND SOCIAL SCIENCES Vol. 8, No. 7, July 2018, E-ISSN: 2222-6990 @ 2018 HRMARS

This part has analysed the health condition among respondents while responding to this survey. It showed a significant result where the $p \leq 0.05$. Most of the respondents rated themselves as good in overall health condition $(n=108)$ compared to those who are unwell $(n=42)$. It is to prove that most of the time, their health at a good condition. Emphasizing better health is supported by other previous findings. Participants who had better perceived health status and greater concern for their health tended to adopt more positive health behaviors. Additionally, participants who frequently engaged in health-related discussions had better critical eHealth literacy and were more likely to perceive intention to seek and evaluate health information (Hsu, Chiang and Yang, 2014).

\section{Limitations of the Study}

On the other hand, in spite of these findings about the intention towards online health information seeking, this study had faced some of the challenges. Findings of the study cannot be generalized to other potential respondents as it is only in one faculty with two center programs in which students had participated. Moreover, this study only focuses to only bumiputera and non-bumiputera students and thus, results are limited and not from multi racial respondents. Lastly, time consuming where the researcher only has the chance to meet the respondents after their class had finished.

\section{Conclusion}

Online health information seeking can improve quality of life. In other words, it is actually emphasizing the concept of self-care management among the students. Due to the vast improvement on the use of Internet in global, the HRI can be easily accessed everywhere, particularly in seeking for diseases. Most of the content in health information are including the definition of the disease, the signs and symptoms, ways to treat the disease and can provides a complementary medicine as the alternative for treatment. This cross sectional study has identified either the demographic profile of the undergraduate students can perceived behavioral intention to online health information seeking. Most of the result supported hypotheses where there are no significance difference exist between demographic profile and intention to seek HRI. It means the attitude of these students towards healthcare is less concerned compared to most of the western countries such as US which appropriately used Internet as part of seeking health purpose information. The strategy to increase health awareness among young adults needs an action and thus, it could help them to prevent health problem later in future. Despite any effort to increase the awareness on global health, more research is required to come with new ideas on how to influence in having the intention seeking HRI. This is due to the prevalence of disease which is alarming in the global especially for the life-threating disease such as cardiovascular disease, tuberculosis and cancer.

\section{References}

1. Asibey, B.O., Agyemang, S., and Dankwah, A.B., (2017). The Internet Use for Health Information Seeking among Ghanaian University Students: A Cross Sectional Study. International Journal of Telemedicine and Applications, 2017(1756473), 1-9. 
INTERNATIONAL JOURNAL OF ACADEMIC RESEARCH IN BUSINESS AND SOCIAL SCIENCES

Vol. 8, No. 7, July 2018, E-ISSN: 2222-6990 (C) 2018 HRMARS

2. Baumann, E., Czerwinski, F., and Reifegerste, D., (2017). Gender-Specific Determinants and Patterns of Online Health Information Seeking: Results from a Representative German Health Survey. Journal of Medical Internet Research, 19(4), e92.

3. Cline, R.J., and Haynes, K.M., (2001). Consumer Health Information Seeking on the Internet: The State of the Art. Health Education Research, 16(6), 671-92.

4. Diviani, N., Putte, B.V.D, Giani, S., and Weert, J.CM.V., (2015). Low Health Literacy and Evaluation of Online Health Information: A systematic Review of the Literature. Journal of Medical Internet Research, 17(5), e112.

5. Higgins, O., Sixsmith, J., Barry, M.M., and Domegan, C., (2011). A literature review on health information-seeking behaviour on the web: a health consumer and health professional perspective. Stockholm, Sweden: European Center for Disease Prevention and Control. Retrieved from https://ecdc.europa.eu/sites/portal/files/media/en/publications/Publications/Literatu re\%20review\%20on\%20health\%20informationseeking\%20behaviour\%20on\%20the\%20web.pdf

6. Hsu, W.C., Chiang, C.H., and Yang, S.C., (2014). The Effect of Individual Factors on Health Behaviors among College Students: The Mediating Effects of eHealth Literacy. Journal of Medical Internet Research, 16(12), e287.

7. Jacobs, W., Amuta, A.O., and Jeon, K.C., (2017). Health Information Seeking in the Digital Age: An Analysis of Health Seeking Behavior among US Adults. Cogent Social Sciences, 3(1302785), 1-11.

8. Jadoon, N.A., Zahid, M.F., Mansoorulhaq, H., Ullah, S., Jadoon, B.A., Raza, A., Hussain, M., Yaqoob, R. and Shahzad, M.A., (2011). Evaluation of Internet Access and Utilization by Medical Students in Lahore, Pakistan. BMC Medical Informatics \& Decision Making, 11(37), 1-6.

9. Klonoff, D.C., (2013). The Current Status of mHealth for Diabetes: Will It be the Next Big Thing? Journal of Diabetes Science and Technology, 7(3), 749-758.

10. Lee, K., Hoti, K., Hughes, J.D., and Emmerton, L., (2014). Dr Google and the Consumer: A Qualitative Study Exploring The Navigational Needs And Online Health InformationSeeking Behaviors Of Consumers With Chronic Health Conditions. Journal of Medical Internet Research, 16(12), e262.

11. Nolke, L., Mensing, M., Kramer, A., and Hornberg, C., (2015). Sociodemographic and Health-(Care-) Related Characteristics of Online Health Information Seekers: A CrossSectional German Study. BMC Public Health, 15(31), 1-12. 
INTERNATIONAL JOURNAL OF ACADEMIC RESEARCH IN BUSINESS AND SOCIAL SCIENCES

Vol. 8, No. 7, July 2018, E-ISSN: 2222-6990 @ 2018 HRMARS

12. Norfadzila, S.W.A., Balakrishnan, V., and Abrizah, A., (2012). The Conceptualization of Integrated Consumer Health Informatics Utilization Framework. World Academy of Science, Engineering and Technology; International Journal of Humanities and Social Sciences, 6(3), 286-290.

13. Obasola, O.I., and Agunbiade, O.M., (2016). Online Health Information Seeking Pattern among Undergraduates in a Nigerian University. SAGE Open, 6(1), 1-9.

14. Rowley, J., Johnson, F., and Sbaffi, L., (2017). Gender as an Influencer of Online Health Information-Seeking and Evaluation Behavior. Journal of the Association for Information Science and Technology, 68(1), 36-47.

15. Saner, H., (2016). eHealth: From Unfilled Promises to Large-scale Application. European Journal of Preventive Cardiology, 23(2S), 3-4.

16. Siliquini, R., Ceruti, M., Lovato, E., Bert, F., Bruno, S., Vito, E.D., Liguori, G., Manzoli, L., Messina, G., Minniti, D., and Torre, G.L., (2011). Surfing the internet for health information: an Italian survey on use and population choices. BMC Medical Informatics and Decision Making, 11(21), 1-9. 